\title{
The Effects of Pain Expectancy and Desire for Pain Relief on the Memory of Pain in Half Trail Marathon Runners
}

\author{
Elżbieta A Bajcar' \\ Wojciech Swędzioł ${ }^{2}$ \\ Krzysztof Wrześniewski ${ }^{3}$ \\ Jan Blecharz ${ }^{3}$ \\ Przemysław Bąbel (D) \\ 'Jagiellonian University, Institute of \\ Psychology, Pain Research Group, \\ Kraków, Poland; ${ }^{2}$ University of Physical \\ Education in Kraków, Faculty of Tourism \\ and Recreation, Kraków, Poland; \\ ${ }^{3}$ University of Physical Education in \\ Krakow, Department of Psychology, \\ Kraków, Poland
}

Purpose: It has been shown that the memory of pain induced by running might be underestimated. Our previous study showed the contribution of emotional factors to this process. This study aimed to investigate the cognitive factors that might influence the memory of this type of pain, ie expectancy of pain intensity, expectancy of pain unpleasantness, and desire for pain relief.

Participants and Methods: A total of 49 half-marathon runners rated the intensity and unpleasantness of pain immediately after completing a run and one month later. Participants rated the expected intensity and unpleasantness of the upcoming pain before starting the run, as well as the desire for pain relief after its completion. Those who also participated in the previous edition of the half marathon were asked to recall the pain experienced due to that run.

Results: Participants underestimated remembered pain intensity and unpleasantness. The desire for pain relief mediated the memory of pain intensity $(p<0.05)$, while expectancy of pain intensity influenced memory of pain intensity $(a \times b)$ through its effect on the experienced pain (bootstrapped point estimate $=0.08 ; 95 \%$ CI: 0.02-0.32). The remembered intensity of pain experienced during the previous half marathon affected the current pain experience directly $(p<0.05)$ or indirectly $(a \times b)$ by generating pain-related expectancy (bootstrapped point estimate $=0.11 ; 95 \%$ CI: 0.01-0.46). The cognitive variables did not influence the memory of pain unpleasantness.

Conclusion: The memory of pain induced by sports activity may change due to cognitive factors; however, further research is needed to investigate their role in shaping the memory of the sensory and affective dimensions of pain.

Keywords: memory of pain, pain intensity, pain unpleasantness, expectancy, desire

\section{Introduction}

Memory of pain influences future pain experiences ${ }^{1-3}$ and the willingness to engage in activities associated with pain in the past. ${ }^{4,5}$ The overestimation of memory of pain induced by physical exercise might negatively influence future decisions regarding engaging in sports activity, thus negatively affecting health. On the other hand, underestimating past pain may increase engagement in such activities and contribute to health.

Previous studies showed that the pain induced by running a marathon was remembered as less intense and less unpleasant than it originally was. ${ }^{6,7}$ These data were collected from well-trained athletes who had finished a full marathon. The
Correspondence: Elżbieta A Bajcar Jagiellonian University, Institute of Psychology, Pain Research Group, ul. Ingardena 6, Kraków, 30-060, Poland Tel +48I2663243I

Fax +48I266324I 5

Email elzbieta.bajcar@uj.edu.pl 
current study aimed to examine trail half-marathon participants who varied in terms of seniority and number of marathon starts. We hypothesized that both the intensity and unpleasantness of pain induced by this type of sports activity would be underestimated after a one-month delay (H1).

Two factors significantly influence the memory of pain induced by running a marathon: affect experienced upon completing the run, ${ }^{6}$ and pain felt during recall. ${ }^{7}$ However, the influence of cognitive factors on memories of this type of pain has not yet been investigated. Previous results strongly support the effect of pain-related expectancies on pain perception $^{8,9}$ and suggest their effect on the memory of acute clinical pain. ${ }^{10,11}$ Based on these results, we hypothesized that expectancy of pain intensity and pain unpleasantness induced by physical exercise would contribute to the experience and recollection of pain induced by sports activity (H2).

According to Price, ${ }^{12}$ three different dimensions represent pain: pain intensity, pain unpleasantness, and secondary affect, ie, emotional feelings associated with future implications of having pain. Therefore, the desire for pain relief should also be considered as a factor that affects pain experience and memory of pain. Previous studies have shown that desire for pain relief affects both experimental ${ }^{13,14}$ and clinical pain. ${ }^{15,16}$ Based on these data, we hypothesized that the desire for pain relief would contribute to the recollection of pain induced by sports activity (H3).

Experimental studies show that past pain memory influences subsequent pain experiences. ${ }^{2,3}$ Moreover, pain memories turned out to be a mediator between initial and subsequent pain. ${ }^{3}$ We hypothesized that the recalled pain induced by running would influence the experienced pain intensity and unpleasantness (H4). Based on the findings that cognitive factors may be involved in shaping pain memories, ${ }^{10,11}$ as well as a result suggesting that negative pain memories may lead to the expectancy of greater pain, ${ }^{3}$ we hypothesized that the effect of recalled pain on experienced pain would be mediated by pain expectancy (H5).

\section{Materials and Methods Participants}

A total of 71 half-marathon runners entered the first phase of the study, which was conducted at the starting line of the half marathon. All of them also completed the second phase of the study, which was held at the finishing line of the marathon. The third and final phase of the study, which was conducted online about a month (31.5 \pm 2.4 days $)$ after the half marathon, was completed by 49 (69\%) participants. Only data from those who completed all three phases of the study were included in the analyses (except for the analysis in which the dropouts $(\mathrm{N}=22)$ responses were compared to the final group). Thus, the final sample was 49 participants of Polish Caucasian origin, aged $\mathrm{M}=36.5$ $(\mathrm{SD}=9.10)$ years, including 36 males $(73.5 \%)$ (Figure 1$)$. There were no statistically significant differences between men and women in terms of perceived pain and pain unpleasantness caused by running the marathon $(p>0.05)$. The response rate was much higher than in our previous study on the memory of pain induced by running a marathon $(50 \%$; Bąbel et al 2018). The sex ratio in the study accurately reflects the sex ratio of the marathon runners: a total of 105 runners completed the half marathon, of whom 75 were male (71\%). Characteristics of the study sample are presented in Table 1.

Participants were recruited from the runners of the 7 th "Koniczynka" ("Clover") Trail Half Marathon (THM), held on the 11th of May 2018 in Ojców, Poland. This is

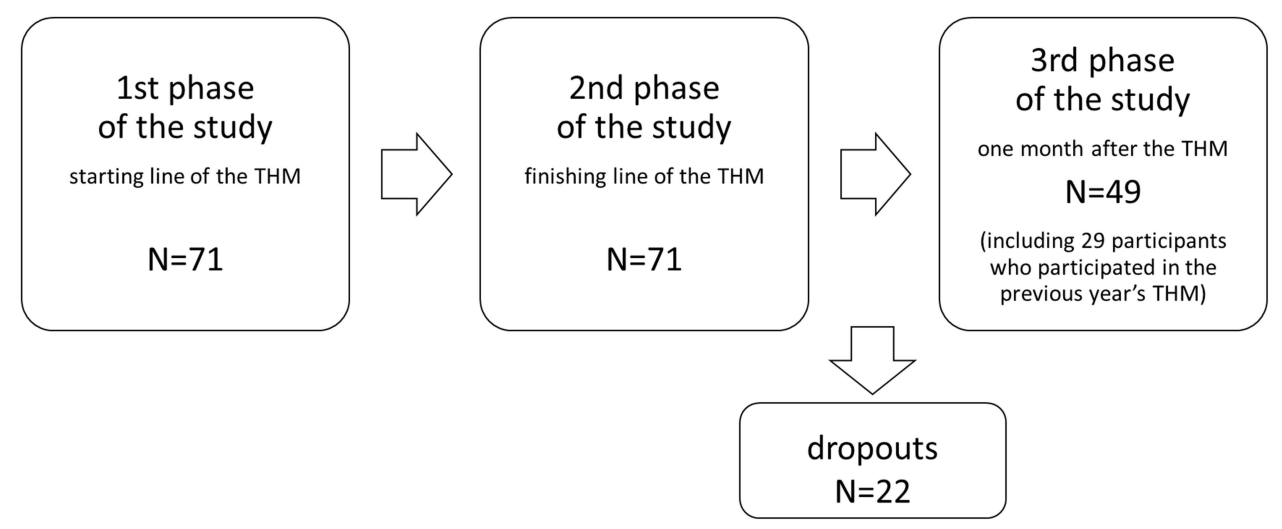

Figure I Flowchart of the study population and sample size for the analysis of memory of pain induced by running. Abbreviation: THM, Trail Half Marathon. 
Table I Characteristics of the Study Sample

\begin{tabular}{|l|c|c|c|c|}
\hline & $\begin{array}{c}\text { Male } \\
\text { N (\%) }\end{array}$ & $\begin{array}{c}\text { Female } \\
\text { N (\%) }\end{array}$ & M & SD \\
\hline $\begin{array}{l}\text { Gender } \\
\text { Age }\end{array}$ & $36(73.5)$ & $13(26.5)$ & - & - \\
$\begin{array}{l}\text { Pain duration after THM } \\
\text { (days) }\end{array}$ & - & - & 36.5 & 9.10 \\
$\begin{array}{l}\text { Years of running } \\
\text { Years of running in }\end{array}$ & - & - & 7.12 & 1.39 \\
marathons & - & - & 5.96 & 4.79 \\
\cline { 2 - 5 } & $\begin{array}{c}\text { No } \\
\text { N (\%) }\end{array}$ & Yes (\%) & M & SD \\
\cline { 2 - 5 } $\begin{array}{l}\text { Participation in running } \\
\text { events after the THM (days } \\
\text { since the last event) }\end{array}$ & $29(59.2)$ & $20(40.8)$ & 12.10 & 8.92 \\
$\begin{array}{l}\text { Pain induced by running } \\
\text { after the THM (days since } \\
\text { the last pain experience } \\
\text { induced by running) }\end{array}$ & $29(59.2)$ & $20(40.8)$ & 8.10 & 7.99 \\
$\begin{array}{l}\text { Pain not induced by running } \\
\text { after the THM (days since } \\
\text { the last pain experience not } \\
\text { induced by running) }\end{array}$ & $28(57.1)$ & 21 (42.9) & 6.00 & 6.24 \\
\hline
\end{tabular}

a mountain run with a distance of $21 \mathrm{~km}$; the sum of the elevations (ascents and descents) is approx. $1200 \mathrm{~m}$. The runners were informed that they would participate in a study on the pain induced by running a half marathon and that the study would comprise three phases. However, they were not informed that the third phase of the study would investigate memory of pain. The runners gave their informed written consent to participate in the study. They were also informed that they could stop participating at any point during the study without giving a reason. No compensation was offered for participation in the study. This study was conducted in accordance with the policies and principles contained in the Declaration of Helsinki. The study protocol was approved by the Research Ethics Committee at the Institute of Psychology of Jagiellonian University.

\section{Measures}

The participants rated expected, experienced and recalled pain intensity, and pain unpleasantness. Intensity of pain was assessed using an 11-point Numeric Rating Scale (NRS), ranging from $0=$ "no pain" to $10=$ "the most intense pain imaginable". Pain unpleasantness was assessed using a similar 11-point NRS, ranging from $0=$ "not at all unpleasant pain" to $10=$ "the most unpleasant pain imaginable". Participants rated the desire for pain relief using an 11-point NRS, ranging from $0=$ "not at all" to $10=$ "very strong". The Numerical Rating Scales are valid tools to measure both sensory and affective dimensions of pain. ${ }^{17-19}$ The NRSs were used in numerous studies to measure the experienced, expected and recalled pain. ${ }^{6,7,20-23}$

Moreover, the participants were also asked about gender, age, THM finishing time, pain duration after the THM, years of running, years of running marathons, the number of running events since the THM, how long since the last running event, whether they had experienced pain induced by running since the THM and how long ago this occurred, whether they had experienced pain since the THM that was not induced by running and how long ago this occurred, and whether they had participated in the previous year's THM.

\section{Procedure}

The study consisted of three phases (Figure 2). The first was conducted at the starting line of the THM. Each marathon runner was individually invited to participate in the study; if they agreed, they signed the consent form and the survey was conducted. In this phase, participants were asked about their age and gender. On two separate NRSs, they then rated how intense and unpleasant they expected the pain would be at the finishing line of THM. They were also asked whether they had participated in the previous year's THM; if so, on the two NSRs they rated the pain intensity and unpleasantness that had been experienced.

The second phase of the study was conducted immediately after each participant had reached the finishing line of the THM. The participants were asked about their THM finishing time, and on the NRSs they rated pain intensity, pain unpleasantness and the desire for pain relief that was felt at that moment.

One month after completion of the THM, the third phase of the study was conducted. The participants were emailed a link to the online survey, which consisted of questions (answered using two NRSs) about the intensity and the unpleasantness of pain experienced immediately upon completing the THM. It was emphasized that they should recall and rate how they remembered the pain they felt during the second phase of the study rather than recall how they had rated the pain on the same scales in the second phase of the study. The participants declared for how many days they had felt pain after completing the 


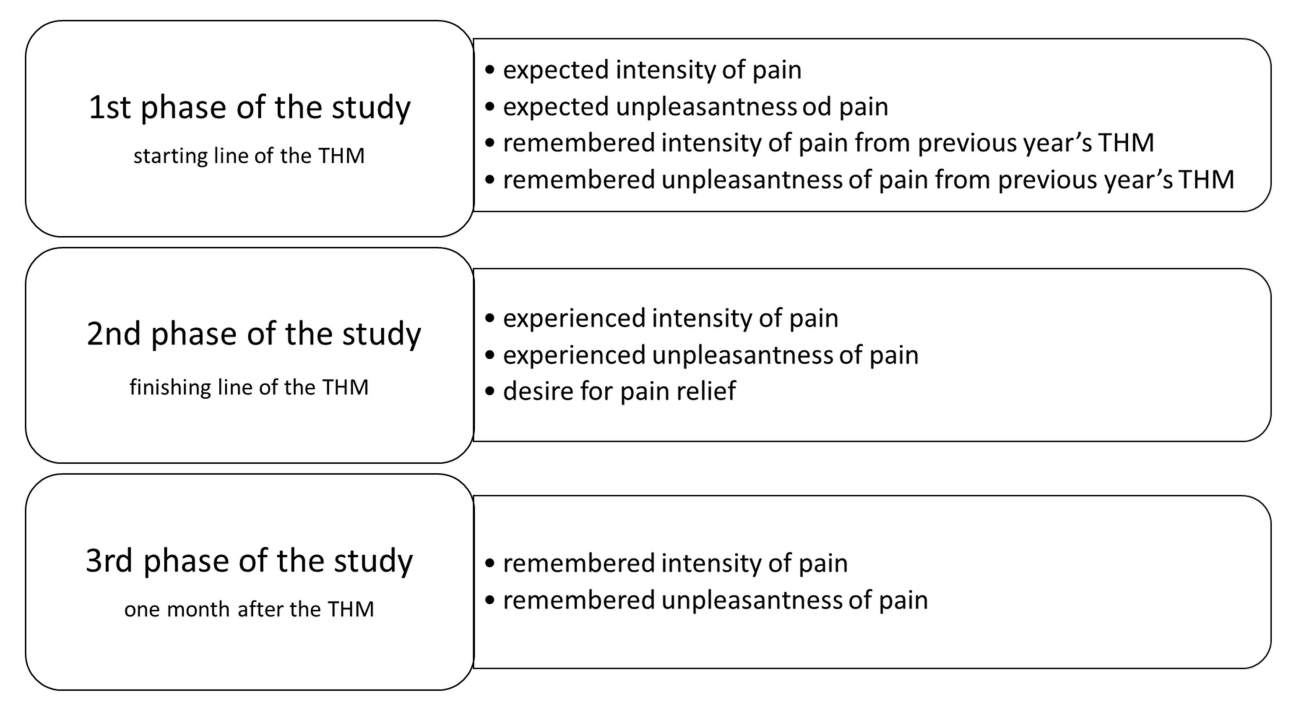

Figure 2 The timeline of the study. Pain measurements during subsequent phases of the study. Abbreviation: THM, Trail Half Marathon.

THM. They were also asked whether they felt pain when they completed the survey and to rate the intensity and unpleasantness of that pain. Moreover, respondents reported their running experience, ie how long they had been running, how many years they had been participating in marathons, the number of running events they had participated in since the THM, how long ago the last event took place, whether they had experienced pain induced by running since the THM, how long ago the last experience took place, whether they had experienced pain not induced by running since the THM, and how long since the last running experience. As the questions were asked during the third phase of the study, the answers refer to the participants' experiences until the moment of pain recall.

The participants were asked to complete the online survey as soon as possible. Those who did not answer the questions on the day when the link to the online survey was sent were prompted one day later to respond. They were asked to answer the questions within a day. Two days after the initial e-mail was sent, the online survey was closed and participants were unable to complete it anymore.

\section{Statistical Analysis}

$t$-tests were used to compare the final sample and dropouts in terms of expected and experienced pain intensity and expected and experienced pain unpleasantness after completion of the marathon.
Two repeated-measures analyses of variance (ANOVA) were used to compare pain intensity and pain unpleasantness in three periods of time (expected, experienced and recalled pain intensity and unpleasantness). $F$-tests were followed by Bonferroni tests on the expected versus experienced versus recalled pain intensity and pain unpleasantness (H1).

Four mediation analyses were performed to verify whether experienced pain intensity or unpleasantness or desire for pain relief $(\mathrm{M})$ mediated the relation between the independent variable (X: experienced or expected pain intensity or unpleasantness) and the dependent variable (Y: recalled pain intensity or unpleasantness) (H2, H3). Then, two mediation analyses were performed to verify whether expected pain intensity or unpleasantness (M) mediated the relation between the independent variable (X: recalled pain intensity or unpleasantness from the previous THM) and the dependent variable ( $Y$ : experienced pain intensity or unpleasantness) (H4). These mediation analyses were conducted on 29 participants who completed the previous year's THM.

Mediation analyses were conducted using the crossproduct of the widely applied and recommended coefficients approach. ${ }^{24}$ In this approach, the significance of the indirect effect $(\mathrm{a} x \mathrm{~b})$ is tested, which is a product of the relation between X and M (path "a") multiplied by the product of the relation between $\mathrm{M}$ and $\mathrm{Y}$, controlling for X (path " $\mathrm{b}$ "). The significance of the indirect effect was tested using a nonparametric bootstrap approach. ${ }^{25} \mathrm{~A}$ bias-corrected confidence interval, based on 5000 bootstrapped samples and correction for heteroscedasticity, was provided for the tested 
mediators. ${ }^{25,26}$ Confidence intervals (CI) are derived from the obtained distribution of $\mathrm{a} x \mathrm{~b}$ scores. If the lower and upper CI bounds do not contain zero, then the indirect effect is significant at the level obtained in the analysis.

Statistical analyses were conducted using the IBM SPSS Statistics ver. 26 software package (SSPS Inc., Chicago, Illinois, USA) with the PROCESS macro. The level of significance was set at $p<0.05$ in order to reject the null hypothesis in all the statistical analyses.

\section{Results}

Between the final study sample and participants who did not reply to the follow-up e-mail, there was no difference in terms of expected pain intensity $(t(46.8)=-0.217 ; p=$ $0.829)$, expected pain unpleasantness $(t(34.2)=-0.430$; $p=0.670)$, experienced pain intensity $(t(44.5)=-0.574$; $p=0.569)$ and experienced pain unpleasantness $(t(50.6)=$ $-0.228 ; p=0.821)$. Descriptive statistics for participants' pain ratings are presented in Table 2.

The ANOVA for pain intensity revealed a statistically significant effect $\left(F_{(2,47)}=9.469, p<\right.$ $\left.0.001, \eta_{P}^{2}=0.165\right)$. Bonferroni tests found significant differences between experienced and recalled pain intensity $(p<0.001)$, expected and recalled pain intensity $(p<0.001)$, but not between expected and experienced pain intensity. Recalled pain intensity after THM was lower than expected pain intensity before THM and
Table 2 Descriptive Statistics for Dependent Variables: Pain Ratings

\begin{tabular}{|l|c|c|}
\hline & M & SD \\
\hline Expected pain intensity before THM & 4.27 & 2.44 \\
Expected pain unpleasantness before THM & 3.43 & 2.32 \\
Experienced pain intensity after THM & 4.29 & 2.58 \\
Experienced pain unpleasantness after THM & 3.57 & 2.65 \\
Desire for pain relief after THM & 4.12 & 3.82 \\
Recalled pain intensity after THM & 3.16 & 2.34 \\
Recalled pain unpleasantness after THM & 2.47 & 2.15 \\
Experienced pain intensity during recall & 0.80 & 1.55 \\
Experienced pain unpleasantness during recall & 0.86 & 1.81 \\
Recalled pain intensity from previous THM (N=29) & 4.07 & 2.79 \\
Recalled pain unpleasantness from previous THM & 3.21 & 2.43 \\
(N=29) & & \\
\hline
\end{tabular}

experienced pain intensity after THM (Figure 3). Analogously, the ANOVA for pain unpleasantness revealed a statistically significant effect $\left(F_{(2,47)}=\right.$ 4.735, $\left.p<0.001, \eta_{P}^{2}=0.09\right)$. Bonferroni tests found significant differences between experienced and recalled pain unpleasantness $(p<0.05)$, expected and recalled pain unpleasantness $(p<0.05)$, but not between expected and experienced pain unpleasantness. Recalled pain unpleasantness after the THM was lower than expected pain unpleasantness before the THM and experienced pain unpleasantness after the THM (Figure 3).

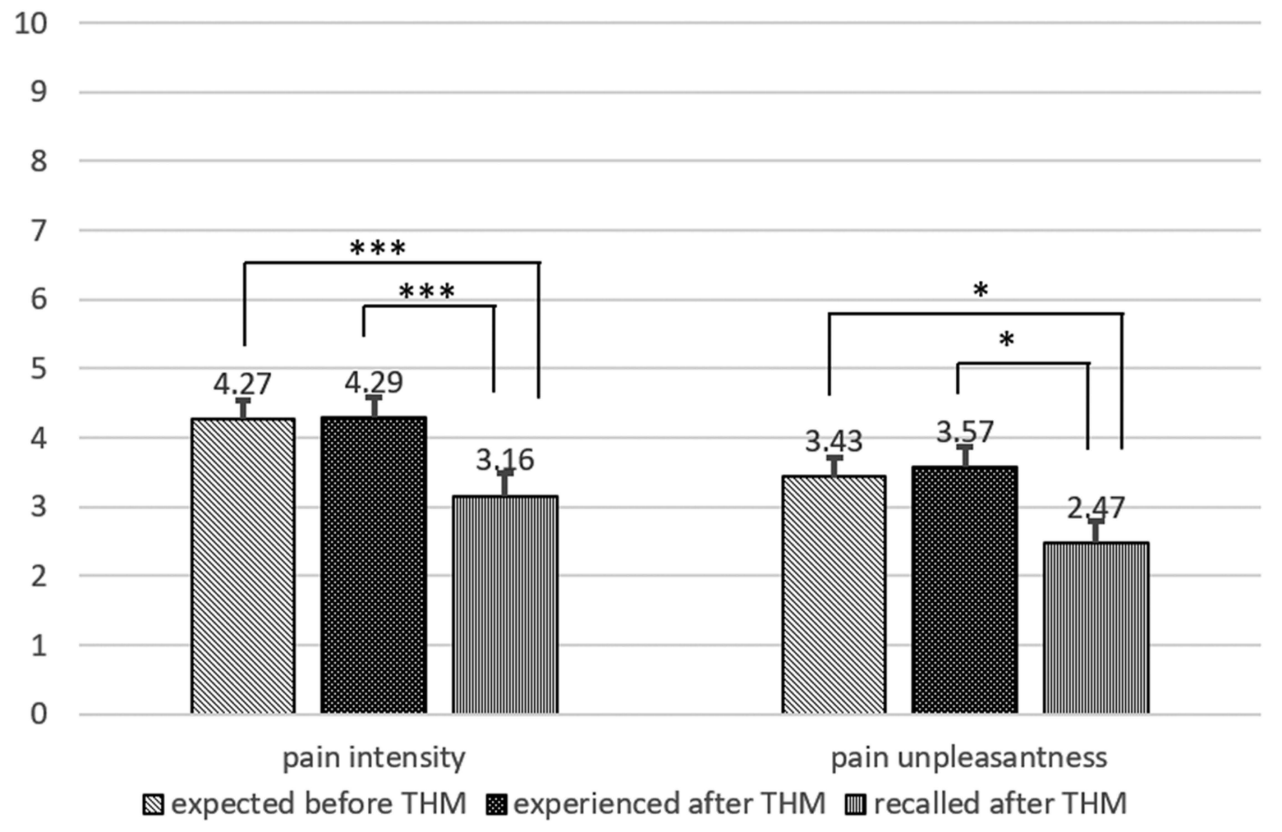

Figure 3 NRS expected, experienced, and recalled pain intensity and unpleasantness. Error bars represent the SE. $*_{p}<0.05$; $* * * p<0.00$ I. Abbreviation: THM, Trail Half Marathon. 


\section{Mediation Analyses}

Experienced pain intensity after the THM mediated recalled pain intensity after the THM. Expected pain intensity before the THM (X) was positively related to experienced pain intensity after the THM (M) $(a=0.68 ; p<0.001)$. Experienced pain intensity after the THM (M) was positively related to recalled pain intensity after the THM (Y) while controlling for expected pain intensity before the THM (X) $(b=0.58 ; p<0.001)$. Thus, expected pain intensity (X) indirectly $(a \times b)$ influenced recalled pain intensity $(\mathrm{Y})$ through its effect on experienced pain intensity (M) (bootstrapped point estimate $=0.10 ; 95 \%$ CI: $0.20-0.61)$. The direct effect of expected pain intensity $(\mathrm{X})$ on recalled pain intensity (Y) was not significant $\left(c^{\prime}=0.14 ; p>0.05\right)$, thus indicating that only the indirect path that explains recalled pain intensity is possible (Table 3 and Figure 4). There was no significant effect for recalled pain unpleasantness, while the mediator was experienced pain unpleasantness after the THM (Table 3).

Desire for pain relief after the THM significantly mediated recalled pain intensity after the THM. Experienced pain intensity after the THM (X) was positively related to desire for pain relief after the THM (M)
( $a=0.79 ; p<0.001)$, and desire for pain relief after the THM (M) was positively related to recalled pain intensity after the THM (Y) while controlling for experienced pain intensity after the THM (X) $(b=0.19 ; p<0.05)$. Thus, experienced pain intensity (X) indirectly $(a \times b)$ influenced recalled pain intensity $(\mathrm{Y})$, through its effect on desire for pain relief $(\mathrm{M})$ (bootstrapped point estimate $=$ 0.08; 95\% CI: 0.02-0.32). Nevertheless, the direct effect of experienced pain intensity after the THM (X) on recalled pain intensity after the THM $(\mathrm{Y})$ was still significant $\left(c^{\prime}=0.52 ; p<0.001\right)$, thus indicating that direct and indirect paths that explain recalled pain intensity after the THM are equally possible (Table 3 and Figure 5). There was no significant mediation effect for recalled pain unpleasantness after the THM, while the mediator was desire for pain relief after the THM (Table 3).

In the sample of 29 participants who had participated in the previous year's THM (all of them finished the marathon), expected pain intensity mediated experienced pain after the THM. Recalled pain intensity from the previous THM (X) was positively related to expected pain intensity before the current THM (M) $(a=0.63 ; p<$

Table 3 Results of the Mediation Analysis for Recalled Pain $(N=49)$

\begin{tabular}{|c|c|c|c|c|c|c|c|c|c|}
\hline \multirow[t]{2}{*}{$\begin{array}{l}\text { Dependent } \\
\text { Variable }\end{array}$} & \multirow[t]{2}{*}{ Mediator } & \multirow[t]{2}{*}{ Path } & \multicolumn{4}{|c|}{ Normal Theory Test } & \multicolumn{3}{|c|}{$\begin{array}{l}\text { Bootstrap Results for Indirect } \\
\text { Effect }(95 \%, \mathrm{Cl})\end{array}$} \\
\hline & & & Coefficient & $S E$ & $\mathbf{t} / \mathbf{z}$ & $\mathbf{p}$ & $\begin{array}{l}\text { Estimate } \\
\text { Point SE }\end{array}$ & Lower & Upper \\
\hline Expected pain & Experienced pain & a & 0.68 & 0.12 & 5.70 & $<0.001$ & \multirow{9}{*}{0.10} & \multirow{9}{*}{0.2} & \multirow{9}{*}{0.61} \\
\hline \multirow[t]{4}{*}{ intensity } & intensity & b & 0.58 & 0.12 & 5.01 & $<0.001$ & & & \\
\hline & & Total (c) & 0.54 & 0.12 & 4.66 & $<0.001$ & & & \\
\hline & & Direct (c') & 0.14 & 0.12 & 1.20 & 0.24 & & & \\
\hline & & Indirect $(\mathrm{a} \times \mathrm{b})$ & 0.40 & & & & & & \\
\hline Expected pain & Experienced pain & a & 0.50 & 0.15 & 3.33 & 0.02 & & & \\
\hline \multirow[t]{4}{*}{ unpleasantness } & unpleasantness & b & 0.42 & 0.12 & 3.60 & $<0.001$ & & & \\
\hline & & Total (c) & 0.10 & 0.13 & 0.75 & 0.46 & & & \\
\hline & & Direct $\left(c^{\prime}\right)$ & -0.11 & 0.13 & -0.81 & 0.42 & & & \\
\hline & & Indirect $(a \times b)$ & 0.21 & & & & \multirow[t]{5}{*}{0.09} & \multirow[t]{5}{*}{0.06} & \multirow[t]{5}{*}{0.41} \\
\hline Experienced pain & Desire for pain & $\mathrm{a}$ & 0.79 & 0.18 & 4.31 & $<0.001$ & & & \\
\hline \multirow{4}{*}{ intensity } & relief & b & 0.19 & 0.07 & 2.79 & $<0.01$ & & & \\
\hline & & Total (c) & 0.67 & 0.09 & 7.48 & $<0.001$ & & & \\
\hline & & Direct (c') & 0.52 & 0.10 & 5.28 & $<0.001$ & & & \\
\hline & & Indirect $(a \times b)$ & 0.15 & & & & \multirow[t]{5}{*}{0.08} & \multirow[t]{5}{*}{0.02} & \multirow[t]{5}{*}{0.32} \\
\hline Experienced pain & Desire for pain & $\mathrm{a}$ & 0.96 & 0.69 & 0.98 & 0.33 & & & \\
\hline unpleasantness & relief & $b$ & 0.12 & 0.10 & 1.28 & 0.21 & & & \\
\hline & & Total (c) & 0.37 & 0.10 & 3.32 & $<0.001$ & & & \\
\hline & & Direct (c') & 0.26 & 0.14 & 1.85 & 0.07 & & & \\
\hline & & Indirect $(\mathrm{a} \times \mathrm{b})$ & 0.12 & & & & 0.10 & -0.06 & 0.35 \\
\hline
\end{tabular}




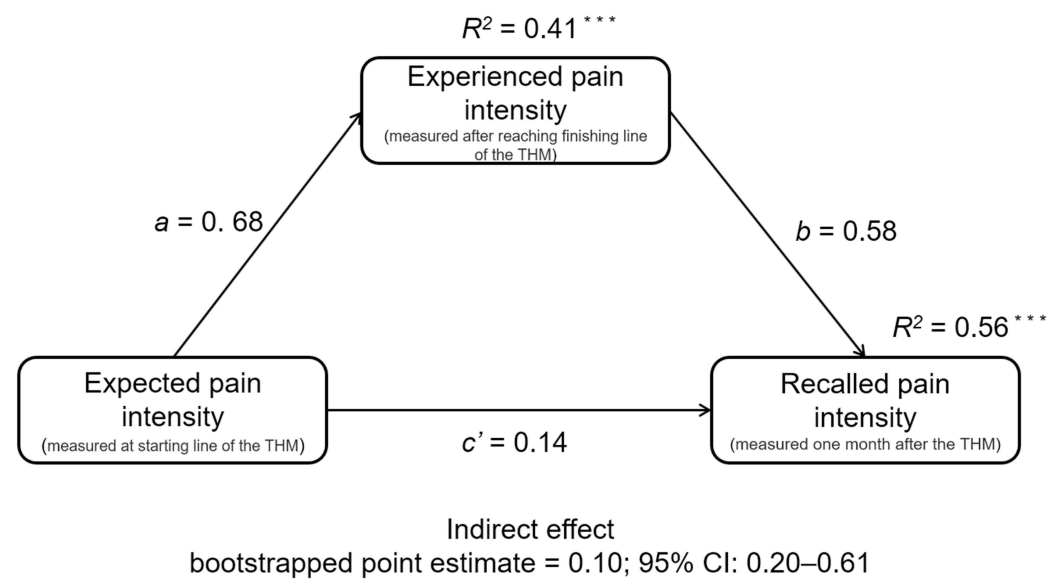

Figure 4 Experienced pain intensity after the Trail Half Marathon (THM) as a mediator of the relationship between expected pain intensity before the THM and recalled pain intensity after the THM. Unstandardized path coefficients and amounts of accounted variance (R2) in the dependent variables are provided. $* * * p<0.00 \mathrm{I}$.

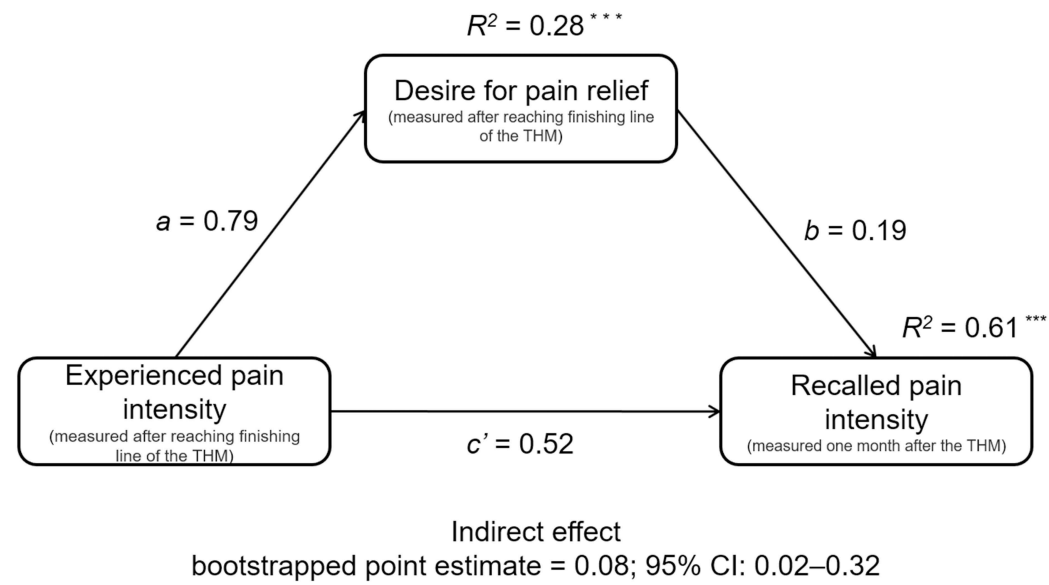

Figure 5 Desire for pain relief after the Trail Half Marathon (THM) as a mediator of the relationship between experienced pain intensity before the THM and recalled pain intensity after the THM. Unstandardized path coefficients and amounts of accounted variance $\left(\mathrm{R}^{2}\right)$ in the dependent variables are provided. $* * * p<0.00 \mathrm{I}$.

0.001), and expected pain intensity before the THM (M) was positively related to experienced pain intensity after the THM (Y) while controlling for recalled pain intensity from the previous THM (X) $(b=0.36 ; p<0.05)$. Thus, recalled pain intensity $(\mathrm{X})$ indirectly $(a \times b)$ influenced experienced pain intensity (Y) through its effect on expected pain intensity (M) (bootstrapped point estimate $=0.11 ; 95 \%$ CI: 0.01-0.46). Nevertheless, the direct effect of recalled pain intensity $(\mathrm{X})$ on experienced pain intensity (Y) was still significant $\left(c^{\prime}=0.44 ; p<0.05\right)$, indicating that both direct and indirect paths that explain the experienced pain intensity are equally possible (Table 4 and Figure 6). There was no significant mediation effect for experienced pain unpleasantness after the THM, while the mediator was expected pain unpleasantness after the THM (Table 4).

\section{Discussion}

The current study showed that pain induced by running a half marathon is remembered as less intense and less unpleasant than it originally was. Cognitive factors, ie, the expectancy of the upcoming pain intensity and the desire for pain relief, contributed to underestimation of the memory of pain intensity but not its unpleasantness. The desire for pain relief significantly mediated the memory of pain intensity, while expectancy of pain intensity influenced memory of pain intensity through its effect on the experienced pain. Moreover, the memory of pain intensity induced by previous sports activity both directly and indirectly influenced the current pain experience by generating pain-related expectancy.

One of the current research conclusions is that the memory of both the intensity and unpleasantness of pain 
Table 4 Results of Mediation Analysis for Experienced Pain ( $N=29)$

\begin{tabular}{|c|c|c|c|c|c|c|c|c|c|c|}
\hline \multirow[t]{2}{*}{$\mathbf{x}$} & \multirow[t]{2}{*}{$\mathbf{Y}$} & \multirow[t]{2}{*}{ Mediator } & \multirow[t]{2}{*}{ Path } & \multicolumn{4}{|c|}{ Normal Theory Test } & \multicolumn{3}{|c|}{$\begin{array}{l}\text { Bootstrap Results for } \\
\text { Indirect Effect }(95 \%, \mathrm{Cl})\end{array}$} \\
\hline & & & & Coefficient & $S E$ & $t / z$ & $\mathbf{p}$ & $\begin{array}{l}\text { Estimate } \\
\text { Point SE }\end{array}$ & Lower & Upper \\
\hline $\begin{array}{l}\text { Recalled pain } \\
\text { intensity from } \\
\text { previous THM } \\
\text { Recalled pain } \\
\text { unpleasantness } \\
\text { from previous } \\
\text { THM }\end{array}$ & $\begin{array}{l}\text { Experienced pain } \\
\text { intensity } \\
\text { Experienced pain } \\
\text { unpleasantness }\end{array}$ & $\begin{array}{l}\text { Expected pain } \\
\text { intensity } \\
\text { Expected pain } \\
\text { unpleasantness }\end{array}$ & $\begin{array}{l}\mathrm{a} \\
\mathrm{b} \\
\text { Total }(\mathrm{c}) \\
\text { Direct }\left(\mathrm{c}^{\prime}\right) \\
\text { Indirect }(\mathrm{a} \times \mathrm{b}) \\
\mathrm{a} \\
\mathrm{b} \\
\text { Total }(\mathrm{c}) \\
\text { Direct }\left(\mathrm{c}^{\prime}\right) \\
\text { Indirect }(\mathrm{a} \times \mathrm{b})\end{array}$ & $\begin{array}{l}0.63 \\
0.36 \\
0.67 \\
0.44 \\
0.23 \\
0.53 \\
0.18 \\
0.84 \\
0.75 \\
0.10\end{array}$ & $\begin{array}{l}0.13 \\
0.14 \\
0.11 \\
0.13 \\
\\
0.65 \\
0.15 \\
0.12 \\
0.15\end{array}$ & $\begin{array}{l}4.73 \\
2.64 \\
6.35 \\
3.42 \\
\\
\\
3.29 \\
1.23 \\
6.75 \\
5.10\end{array}$ & $\begin{array}{l}<0.001 \\
<0.05 \\
<0.001 \\
<0.05 \\
<0.01 \\
0.23 \\
<0.001 \\
<0.001\end{array}$ & 0.037 & -0.02 & 0.13 \\
\hline
\end{tabular}

induced by running is distorted within one month. This result supports the first hypothesis (H1) and is in line with previous studies on the memory of pain induced by running a marathon. ${ }^{6,7}$ One of these studies shows that the memory of this type of pain may start fading even earlier after just one week. ${ }^{7}$ It seems that the memory of pain associated with a positive event tends to be underestimated; such a conclusion can also be drawn from studies on the memory of pain induced by giving birth. ${ }^{27-30}$ Running a marathon, like giving birth, might increase the concentration of beta-endorphins and oxytocin, which in turn impair memory of negative aspects of such experiences, eg, pain. ${ }^{31}$

The current study suggests that the experience and the memory of pain induced by physical effort may change as a result of cognitive factors. The expected intensity of upcoming pain determined the way it was felt. This result aligns with previous studies which showed that expectancy shapes pain experiences. ${ }^{9}$ This result is also in line with the theory proposed by Kirsch, ${ }^{32,33}$ according to which a change in an internal experience, eg, pain, is the result of its expected occurrence. The effect of pain expectancy on subjective pain was also confirmed in neuroimaging studies, especially those conducted in the field of placebo studies. Their results showed that expectancy manipulations affected pain-related regions and produced responses in the thalamus, insula, and anterior cingulate cortex. Moreover, some data shows that psychological factors can block the processing of nociceptive signals even earlier - at the spinal cord level. ${ }^{8}$

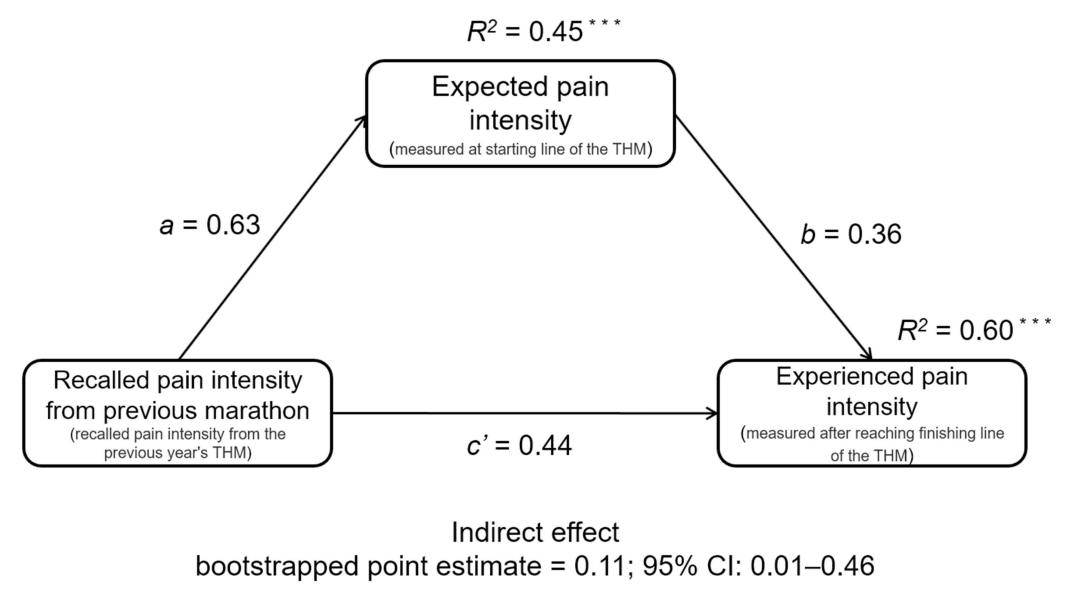

Figure 6 Expected pain intensity before the Trail Half Marathon (THM) as a mediator of the relationship between recalled pain intensity from the previous THM and pain intensity experienced after completing the current THM. Unstandardized path coefficients and amounts of accounted variance $\left(R^{2}\right)$ in the dependent variables are provided. $* * * p<0.001$. 
In the present study, we found no direct effect of expectancy of pain intensity on the memory of pain intensity; however, the expectancy of pain intensity indirectly influenced the memory of pain by modifying the experience of pain. A similar result was found in one previous study on acute pain induced by a medical procedure: the effect of expectancy on pain recall was shown to be mediated by the variability of pain levels experienced during the procedure. ${ }^{10}$ Based on these results and theoretical premises concerning the effects of expectancy on pain, ${ }^{32,33}$ we can speculate that expectancy of pain intensity primarily influences pain processing. Interestingly, pain-related expectancy did not affect the memory of pain unpleasantness. This result provides further evidence that pain is a multidimensional phenomenon and that its sensory and affective aspects may undergo various changes even though they are interrelated. ${ }^{12,34}$ This result is also in line with previous findings showing that pain intensity and unpleasantness may be remembered differently ${ }^{28,35}$ and that the memory of each of these two pain dimensions may be shaped by various factors. ${ }^{36}$ Overall, the collected data only partially support the second hypothesis (H2) as they show the effect of the expected pain intensity but not the effect of pain unpleasantness on pain perception and the memory of pain induced by running.

In the present study, we found an effect of another cognitive factor, ie the desire for pain relief, on the memory of pain intensity. It has been suggested that the desire for pain relief may be a more important factor in clinical pain, which is open-ended and threatening. ${ }^{37}$ However, it turned out to be a significant mediator of the relationship between experienced and recalled pain intensity induced by physical effort. This result supports the hypothesis regarding the contribution of the desire for pain relief to the recollection of pain induced by running a half marathon (H3). This result also indicates the need to control for the desire for pain relief when studying the memory of pain caused by predictable events with positive emotional valence. A similar conclusion was reached by previous studies which showed that the desire for pain relief contributes not only to clinical pain $^{15,16}$ but also to experimentally induced pain..$^{13,14}$ Interestingly, there was no mediation effect for recalled pain unpleasantness when the mediator was the desire for pain relief. This result is another indication that various factors shape the memory of sensory and affective aspects of pain induced by running.
Most of the research on pain memory focused on factors that contribute to memory distortions. ${ }^{38}$ However, studies have also shown the contribution of pain memory to subsequent pain experiences. ${ }^{2,3}$ The memory of experimentally induced pain was a better predictor of subsequent pain than the intensity of the experienced pain in adults ${ }^{2}$ and children. ${ }^{3}$ Moreover, the relationship between the initial pain and subsequent pain was mediated by the memory of pain. ${ }^{3}$ A similar finding was obtained in the current study: the recalled intensity of past pain influenced the experienced intensity of the current pain. However, the effect of the recalled unpleasantness of pain on the experienced pain unpleasantness has not been demonstrated. Thus, this result only partially supports the hypothesis concerning the influence of the memory of pain induced by running on current pain (H4). Notably, the effect of the memory of pain on current pain was both direct and mediated by expectancy. This result is in line with a previous study which showed that negative pain memories foster the development of negative expectancy. ${ }^{3}$ However, the current study extends previous findings by showing that expectancy mediates the relationship between recalled pain and currently experienced pain, thus confirming the hypothesis (H5).

Some practical implications can be derived from these results. They showed that pain-related expectancies that had been generated by painful physical effort in the past could influence future pain experiences. It seems that reframing these expectancies can be an effective way to enhance people's engagement in sports activities that were associated with pain in the past.

Some limitations of the study should be also acknowledged. One of them was the relatively small group of respondents (especially in the case of a sample of 29 participants who had participated in the previous year's THM), which resulted from the specificity of the event during which the study was conducted: the previous studies' data were collected during international events that attract a large number of runners, ${ }^{6,7}$ but the current data were collected during a local sporting event. It should also be noted that two different data collection methods were used in the course of the study: in the first phase, a paper and pencil method was applied, but an online survey was conducted in the second phase. However, this was also the case in other studies on the memory of pain. ${ }^{2,3,6,7,21}$ In the current study, memory of pain induced by running a half marathon was investigated, and the results may not be generalizable to pain induced by other modes of sports activity. Moreover, the study was conducted in a natural 
setting, which had some advantages - it allowed us to investigate naturally occurring pain and generalize the findings across other similar situations. However, the control for the confounding factors was limited; thus, the observed associations are not casual.

\section{Conclusion}

The current results contribute to the knowledge on the factors that shape the memory of pain, particularly the memory of pain induced by physical exercise. Thus, our study results emphasize the importance of cognitive factors in the memory of pain formation. Moreover, this study shows that although the memory of pain induced by sports activity fades over time, its sensory and affective components are influenced by different variables. Furthermore, the study demonstrates the meaning of the memory of pain induced by physical exercise for future pain expectancy and experience. Unlike previous studies on the memory of pain induced by running a marathon in which trained athletes participated, ${ }^{6,7}$ this study provides information on how this type of pain is perceived and remembered by runners who varied in terms of seniority and number of marathon starts. Future studies should further investigate the factors that influence how the affective aspect of pain induced by physical exercise, ie, pain unpleasantness, is experienced and remembered.

\section{Acknowledgments}

The study was funded by the grant no. 2016/23/B/HS6/ 03890 from the National Science Centre, Poland. The authors would like to thank Katarzyna Supernat, MA and Samuel Nowak, PhD for their assistance in data collection.

\section{Disclosure}

The authors report no conflicts of interest in this work.

\section{References}

1. Chen E, Zeltzer LK, Craske MG, Katz ER. Children's memories for painful cancer treatment procedures: implications for distress. Child Dev. 2000;71(4):933-947. doi:10.1111/1467-8624.00200

2. Gedney JJ, Logan H. Pain related recall predicts future pain report. Pain. 2006;121(1-2):69-76. doi:10.1016/j.pain.2005.12.005

3. Noel M, Chambers CT, McGrath PJ, Klein RM, Stewart SH. The influence of children's pain memories on subsequent pain experience. Pain. 2012;153(8):1563-1572. doi:10.1016/j.pain.2012.02.020

4. Kahneman D, Fredrickson BL, Schreiber CA, Redelmeier DA. When more pain is preferred to less: adding a better end. Psychol Sci. 1993;4 (6):401-405. doi:10.1111/j.1467-9280.1993.tb00589.x

5. Redelmeier DA, Katz J, Kahneman D. Memories of colonoscopy: a randomized trial. Pain. 2003;104(1-2):187-194. doi:10.1016/ S0304-3959(03)00003-4
6. Bąbel P. Memory of pain induced by physical exercise. Memory. 2016;24(4):548-559. doi:10.1080/09658211.2015.1023809

7. Bąbel P, Bajcar EA, Śmieja M, et al. Pain begets pain. When marathon runners are not in pain anymore, they underestimate their memory of marathon pain-a mediation analysis. Eur $J$ Pain. 2018;22(4):800-809. doi:10.1002/ejp.1166

8. Atlas LY, Wager TD. How expectations shape pain. Neurosci Lett. 2012;520(2):140-148. doi:10.1016/j.neulet.2012.03.039

9. Peerdeman KJ, van Laarhoven AIM, Peters ML, Evers AWM. An integrative review of the influence of expectancies on pain. Front Psychol. 2016;7:1270. doi:10.3389/fpsyg.2016.01270

10. Gavaruzzi T, Carnaghi A, Lotto L, et al. Recalling pain experienced during a colonoscopy: pain expectation and variability. $\mathrm{Br}$ $J$ Health Psychol. 2010;15(Pt 2):253-264. doi:10.1348/ 135910709X458305

11. Gedney JJ, Logan H, Baron RS. Predictors of short-term and long-term memory of sensory and affective dimensions of pain. J Pain. 2003;4(2):47-55. doi:10.1054/jpai.2003.3

12. Price DD. Psychological and neural mechanisms of the affective dimension of pain. Science. 2000;288(5472):1769-1772. doi:10. $1126 /$ science. 288.5472 .1769

13. Jegindø EME, Vase L, Skewes JC, et al. Expectations contribute to reduced pain levels during prayer in highly religious participants. J Behav Med. 2013;36(4):413-426. doi:10.1007/ s10865-012-9438-9

14. Rainville P, Bao QVH, Chrétien P. Pain-related emotions modulate experimental pain perception and autonomic responses. Pain. 2005;118(3):306-318. doi:10.1016/j.pain.2005.08.022

15. Vase L, Robinson ME, Verne GN, Price DD. The contributions of suggestion, desire, and expectation to placebo effects in irritable bowel syndrome patients. An empirical investigation. Pain. 2003;105(1-2):17-25. doi:10.1016/S0304-3959(03)00073-3

16. Vase L, Robinson ME, Verne NG, Price DD. Increased placebo analgesia over time in irritable bowel syndrome (IBS) patients is associated with desire and expectation but not endogenous opioid mechanisms. Pain. 2005;115(3):338-347. doi:10.1016/j.pain.2005. 03.014

17. Hjermstad MJ, Fayers PM, Haugen DF, et al. Studies comparing Numerical Rating Scales, Verbal Rating Scales, and Visual Analogue Scales for assessment of pain intensity in adults: a systematic literature review. J Pain Symptom Manage. 2011;41 (6):1073-1093. doi:10.1016/j.jpainsymman.2010.08.016

18. Ferreira-Valente MA, Pais-Ribeiro JL, Jensen MP. Validity of four pain intensity rating scales. Pain. 2011;152(10):2399-2404. doi:10.1016/j.pain.2011.07.005

19. Pagé MG, Katz J, Stinson J, Isaac L, Martin-Pichora AL, Campbell F. Validation of the numerical rating scale for pain intensity and unpleasantness in pediatric acute postoperative pain: sensitivity to change over time. J Pain. 2012;13(4):359-369. doi:10.1016/j.jpain.2011. 12.010

20. Daoust R, Sirois MJ, Lee JS, et al. Painful memories: reliability of pain intensity recall at 3 months in senior patients. Pain Res Manag. 2017;2017:5983721. doi:10.1155/2017/5983721

21. Hovasapian A, Levine LJ. Reappraisal mitigates overestimation of remembered pain in anxious individuals. Cogn Emot. 2016;30 (6):1222-1231. doi:10.1080/02699931.2015.1049937

22. Lackner JM, Jaccard J, Keefer L, et al. The accuracy of patient-reported measures for GI symptoms: a comparison of real time and retrospective reports. Neurogastroenterol Motil. 2014;26 (12):1802-1811. doi:10.1111/nmo.12466

23. Noel M, Rosenbloom B, Pavlova M, et al. Remembering the pain of surgery 1 year later: a longitudinal examination of anxiety in children's pain memory development. PAIN. 2019;160(8):1729-1739. doi: $10.1097 /$ j.pain.0000000000001582

24. MacKinnon D, Fairchild A, Fritz M. Mediation analysis. Ann Rev Psychol. 2007;58(1):593-614. doi:10.1146/annurev.psych.58.110405.085542 
25. Preacher KJ, Hayes AF. SAS procedures for estimating indirect effects in simple mediation models. Behav Res Methods Instrum Comput. 2004;36(4):717-731. doi:10.3758/bf03206553

26. Preacher KJ, Hayes AF. Asymptotic and resampling strategies for assessing and comparing indirect effects in multiple mediator models. Behav Res Methods. 2008;40(3):879-891. doi:10.3758/BRM.40.3.879

27. Aksoy H, Yücel B, Aksoy U, Acmaz G, Aydin T, Babayigit MA. The relationship between expectation, experience and perception of labour pain: an observational study. Springerplus. 2016;5(1):1766. doi:10.1186/s40064-016-3366-Z

28. Bąbel P, Pieniążek L, Zarotyński D. The effect of the type of pain on the accuracy of memory of pain and affect. Eur J Pain. 2015;19 (3):358-368. doi:10.1002/ejp.554

29. Niven CA, Murphy-Black T. Memory for labor pain: a review of the literature. Birth. 2000;27(4):244-253. doi:10.1046/j.1523-536x.20 00.00244.x

30. Waldenström U. Women's memory of childbirth at two months and one year after the birth. Birth. 2003;30(4):248-254. doi:10.1046/ j.1523-536X.2003.00254.X

31. Farley D, Piszczek $€$, Bąbel P. Why is running a marathon like giving birth? The possible role of oxytocin in the underestimation of the memory of pain induced by labor and intense exercise. Med Hypotheses. 2019;128:86-90. doi:10.1016/j.mehy.2019.05.003
32. Kirsch I. Response expectancy as a determinant of experience and behavior. Am Psychol. 1985;40(11):1189-1202.

33. Kirsch I. Response expectancy theory and application: a decennial review. Appl Prev Psychol. 1997;6(2):69-79. doi:10.1016/S09621849(05)80012-5

34. Rainville P, Carrier B, Hofbauer RK, Bushnell MC, Duncan GH Dissociation of sensory and affective dimensions of pain using hypnotic modulation. Pain. 1999;82(2):159-171. doi:10.1016/S03043959(99)00048-2

35. Bąbel P, Krzemień M. Memory of dental pain induced by tooth restoration. Psychol Stud (Mysore). 2015;53(1):6-17.

36. Halicka M, Bąbel P. Factors contributing to memory of acute pain in older adults undergoing planned and unplanned hip surgery. Clin J Pain. 2018;34(6):543-551. doi:10.1097/AJP.0000000000 000568

37. Price DD, Barrell JJ Expectation and desire in pain and pain reduction. In: How Expectancies Shape Experience. American Psychological Association; 1999:145-171. doi:10.1037/10332006

38. Adamczyk WM, Farley D, Wiercioch-Kuzianik K, et al. Memory of pain in adults: a protocol for systematic review and meta-analysis. Syst Rev. 2019;8(1):201. doi:10.1186/s13643-0191115-4
Journal of Pain Research

\section{Publish your work in this journal}

The Journal of Pain Research is an international, peer reviewed, open access, online journal that welcomes laboratory and clinical findings in the fields of pain research and the prevention and management of pain. Original research, reviews, symposium reports, hypothesis formation and commentaries are all considered for publication. The manuscript management system is completely online and includes a very quick and fair peer-review system, which is all easy to use. Visit http:// www.dovepress.com/testimonials.php to read real quotes from published authors. 